\title{
Proposal for Development of a Fragmented Mobile Substation for Treatment of Seasonal Loads
}

\author{
Arnulfo Barroso de Vasconcellos ${ }^{1}$, Dr.; Jéssica Romeiro de Carvalho ${ }^{1}$, Acad.; \\ Marina Silva Camillo de Carvalho ${ }^{1}$, Acad.; Marllon Welter Schlischting ${ }^{1}$, Acad; Teresa Irene Ribeiro de \\ Carvalho Malheiro, $\mathrm{PhD}^{2}$; Luciano Vogel Dutra, Eng ${ }^{3}$; Wagner Gentil, $\mathrm{Adm}^{3}$ \\ ${ }^{1}$ Faculty of Architecture, Engineering and Technology, UFMT -Federal University of Mato Grosso - \\ Cuiabá/MT - Av. Fernando Correa da Costa, nº 2367 - Bairro Boa Esperança. Cuiabá - MT, Brazil \\ Phone: +55 (65) 3615-8000, e-mail: Arnulfo@ufmt.br, jessica.romeiro@ hotmail.com , \\ marsccarvalho@gmail.com, marllon.schlischting@gmail.com .
}

${ }^{2}$ Federal Institution of Education, Science and Technology of Mato Grosso - IFMT - Avenida Sen. Filinto Müller , 953

Phone: +55 (65) 3616-4100,e-mail: malheiro.teresa@gmail .

\author{
${ }^{3}$ Utility Energisa/Cemat- Cuiabá/MT - Rua Manoel dos Santos Coimbra, 184 \\ Phone: +55 65 3316-5465,e-mail: luciano.vogel@cemat.com.br, wagner.gentil@ cemat.com.br.
}

\begin{abstract}
.
Currently existing mobile substations in the market are characterized by a unique set involving protection, switches, transformer and others. This set has considerable weight and size, making it difficult to trafficability and mobility, due to limitations imposed by DNIT, besides the size and characteristics of the road network in the state of Mato Grosso. This article discusses a concept of fragmented mobile substation modules. This new proposal will provide a faster service by avoiding monetary penalties by indicators of continuity, and diversity into emergency care, as well as in meeting seasonal peak demands of certain regions of the Mato Grosso due to the characteristics of industries that comprise the agribusiness. This article addresses some additional advantages in the use of vegetable oils as compared to mineral oil. The use of vegetable oil as well as presenting technical advantages reduces possible harm to the environment during the displacement of the mobile substation.
\end{abstract}

\section{Key words}

Agribusiness, mobility, seasonality, substation, trafficability.

\section{Introduction}

The state of Mato Grosso (MT) has an area of $903,386.1 \mathrm{~km}^{2}$ with plateaus and mesas in the center, with lowland swamps in the west and dips in the north and residual plateaus. MT has an average demand of active power around 1.5 GW and a power consumption of 5,600 GWh with increasing expansion characteristics with the entry of new industries in the agribusiness sector.
However, this growth is not accompanied by transport infrastructure despite the flow of production largely be done by road. MT has $84,200 \mathrm{~km}$ of highways, 7 federal highways (BR-070, BR-163, BR-364, BR-158, BR-174, BR-242, BR-251) totaling $4000 \mathrm{~km}$, and about 165 state highways totaling $20,000 \mathrm{~km}$, and also municipal roads totaling about 60,000 kilometers.

Of this total, $4,500 \mathrm{~km}$, around $5 \%$ are paved, of which $2,711 \mathrm{~km}$ which corresponds to $68.6 \%$ are under federal jurisdiction, leaving approximately $1,789 \mathrm{~km}$ of paved state highways. In this context, MT has a high percentage of unpaved roads, $21 \%$ of the federal highway system, $89.3 \%$ of the state grid and almost all the municipal grid.

Here it is analyzed the location of fixed substations of Regional Service Centers of the Company of Electricity, as well as their access conditions, stress levels, characteristics of loads served by them and the situation of power transformers [5] that meet the seasonal loads that make up the industrial linked to agribusiness. In this context, we analyzed the technical and economic feasibility of using fragmented mobile substations to meet areas of difficult access that feature active power demands with seasonal characteristics relating to compliance with maximum demands of certain regions of the state of Mato Grosso, due to the characteristics of industries that comprise the agribusiness, as well as problems in the protection, switching and so on. 


\section{Analysis of contents of continuity dec / fec of the utility}

The National Electric Energy Agency - ANEEL uses some indexes for checking the quality of services provided by electric utilities to their customers [1]. The main ones are: Average Interruption Duration per Consumer (DEC) measured in hours and Equivalent Frequency of Interruptions per Consumer (FEC) measured in number of times. In addition, the local Company of Electricity accompanies Mean Time to Service (TMA) measured in minutes, which shows the average time in which they met the complaints and requests of customers.

In 2012, the DEC indicator showed an increase of $16.10 \%$, and $15.90 \%$ of the FEC, as can be seen in table I. These increases were driven during the rainy season, in the months from september to December. It contributed to the increase in accidental occurrences such as falls from tree branches, advertising boards, among others.

To reduce these rates, in 2013, the local company of Electricity improved in service and maintenance facilities, and investments in critical points of the system, such as improving the grounding of some lines of distribution system, construction of feeder and booster substation.

The TMA showed an increase of $11.80 \%$ over the previous year as a result of accidental FEC (mentioned previously), which resulted in a considerable increase in the number of service orders during the rainy season. So this new design in a fragmented mobile substation can contribute to better outcome in the continuous service of the dealership.

TABLE I - Service continuity indices

\begin{tabular}{|l|c|c|c|}
\hline & $\mathbf{2 0 1 2}$ & $\mathbf{2 0 1 1}$ & $\begin{array}{c}\text { Var. 2011 - 2012 } \\
(\boldsymbol{\%})\end{array}$ \\
\hline DEC & 33,9 & 29,2 & $16,10 \%$ \\
\hline FEC & 24,1 & 20,8 & $15,90 \%$ \\
\hline TMA & 253,4 & 226,6 & $11,80 \%$ \\
\hline
\end{tabular}

\section{Seasonal Analysis of The Electrical System}

To analyze the pattern of seasonal loads to be served by a fragmented mobile substation raising the profile of the fixed substations belonging to the Regional Service Centers dealership located in Sinop, Tangara da Serra, Barra do Garças, Cáceres, Confresa, Juína, Rondonópolis and Metropolitan Area Cuiabá was conducted.

Through this survey can be seen that several substations that serve rural loads have increased the loading of transformers at certain times of the year due to harvesting, drying and storage of products related to agribusiness. Therefore, during the months when increased solicitation of active power demand due to the seasonal nature of the charges occurs, there is an overload on the transformers [7]-[8]-[9] that can be detrimental to the continuity of care of Consumer Units.

As the characteristics of the loads of agribusiness occur three to four months during the year alternately in substations which form part of the Regional Service Centers, investments to increase the capacity of various fixed substations are not consistent with reasonable tariffs. However, with the fragmented mobile substation seasonal loads served by substations of various Regional Service Centers could be met, since the seasonal power demands that are part of agribusiness, such as irrigation, planting limestone, grain crushing, storing, among others, do not occur in the same period.

Analyzing the conditions of the state and federal highways that connect the various cities where they are located substations of Regional Service Centers serving seasonal loads, can be seen through the surveys conducted, many of which are paved and natural roads are not in good traffic. However, the fragmentation of the mobile substation into two modules, one composed of the mobile processor in a semitrailer and another composed of the AT and BT modules in two semi-facilitate mobility roadways with limited access due to maintenance conditions and lack of infrastructure.

To analyze the loading of transformers substations belonging to the Regional Service Centres, the analysis of the voltages of the various substations in the municipalities of Mato Grosso served by the local Company of Electricity was performed.

With this information the raising of the level of bus voltage substations that had characterized the care of non-urban loads was performed. Thus, it was decided that the mobile substation transformer would be for primary nominal voltages of $138 \mathrm{kV}$ and $69 \mathrm{kV}$ and secondary rated voltages of $34.5 \mathrm{kV}$ and $13.8 \mathrm{kV}$ substations because the predominance of seasonal loads of $69 \mathrm{kV}$ and $138 \mathrm{kV} \mathrm{[6].}$

It is shown in this paper two examples that illustrate the seasonality. The substation in the city of Sorriso serving seasonal loads due to agribusiness, and the substation of Rondonópolis showing seasonality based on the average temperature of the region.

\section{Transformer characteristics of $69 \mathrm{kV}$ bus of the city of Sorriso}

The economy of the municipality of Sorriso is directly related to agribusiness, being the cultivation of soybeans the main activity. It is considered the largest soy producer in the country. In the municipality are installed multinationals such as Archer Daniels Midland (ADM), Bunge, Cargill, Dreyfus, Glencore and Noble, as well as regional companies as Amaggi, Coacen, Fiagril and Multigrain among others. Also highlights the production of cotton and corn. It also has two poultry slaughterhouses, abattoirs, two pisciculture and three swines with the installation of another prediction for 2013. It is the county that individually produces more grains in Brazil: 3\% of national production and 17\% of state production. In its 600,000 hectares agricultural it produces over 1.8 million tons of grain, and 26400 tons of cotton. Soybean is the main crop, reaching almost $84 \%$ of production.

Figures 1, 2 and 3 illustrate the three-phase current, the apparent phase power and active power demand of the transformer 02 of the $69 \mathrm{kV}$ substation bus in the city of Sorriso during the period of one year. One can notice a significant increase in demand of active 
power in figure 3, in the months of May, June and July which is coincident with the agribusiness activities related to harvesting, drying and storing grain.

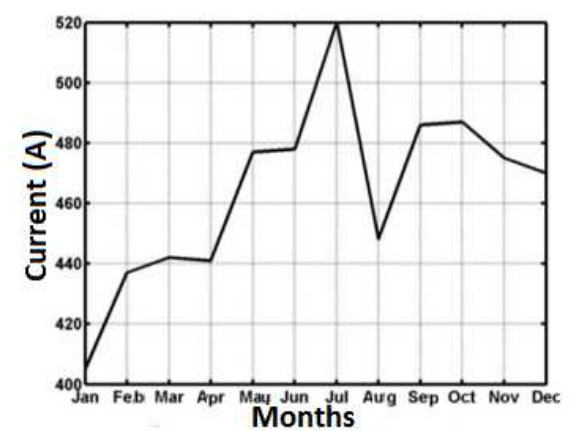

Fig. 1- Secondary phase current of the transformer 02 of 69 $\mathrm{kV} / 13.8 \mathrm{kV}$ and 12.5 MVA substation in city of Sorriso.

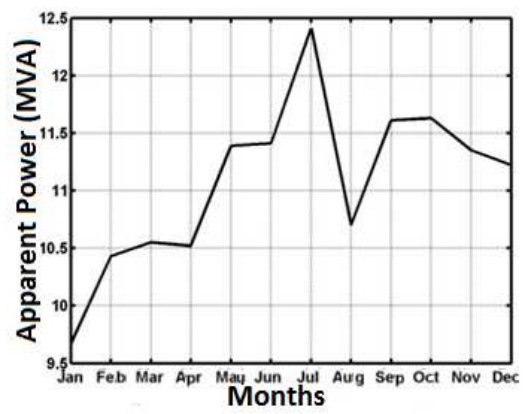

Fig. 2 - Apparent power of the transformer 02 of $69 \mathrm{kV} / 13.8 \mathrm{kV}$ and 12.5 MVA substation in the city of Sorriso.

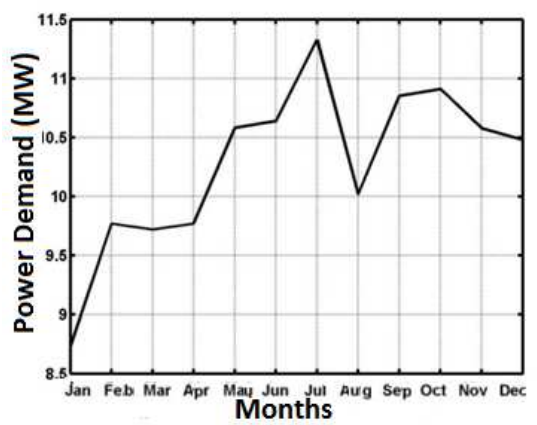

Fig. 3 - Demand for active power transformer 02 of $69 \mathrm{kV} / 13.8$ $\mathrm{kV}$ and 12.5 MVA substation in the municipality of Sorriso.

The weather file in the city of Sorriso using EnergyPlus software to draw the profile of the average monthly temperatures for the year 2012 is illustrated in figure 4 . Figure 4 shows that despite temperatures in the months of August, September and October remain high, there is a reduction in demand for real power, as illustrated in figure 3 , verifying characteristics of seasonality in the loading of the transformer in the months of May, June and July for the agribusiness in the harvesting, storage and grain drying.
Monthly Average Temperature of the City of Sorriso $\left({ }^{\circ} \mathrm{C}\right)$

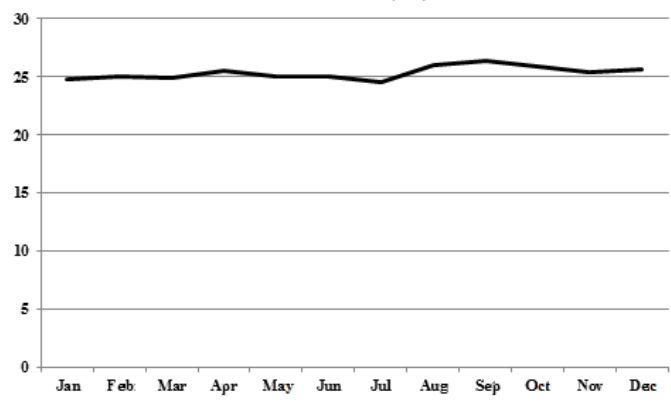

Fig. 4 - Monthly Average Temperature of the city of Sorriso.

\section{Characteristics of transformers bus 138 $\mathrm{kV}$ of the city of rondonópolis}

Figures 5, 6 and 7 illustrate the phase current, the apparent phase power and active power demand of the transformer 01 of $138 \mathrm{kV}$ substation bus in the city of Rondonópolis during the period of one year. One can notice a significant increase in active power demand in the months of September, October and November due to the climatic conditions of the region where the municipality is located.

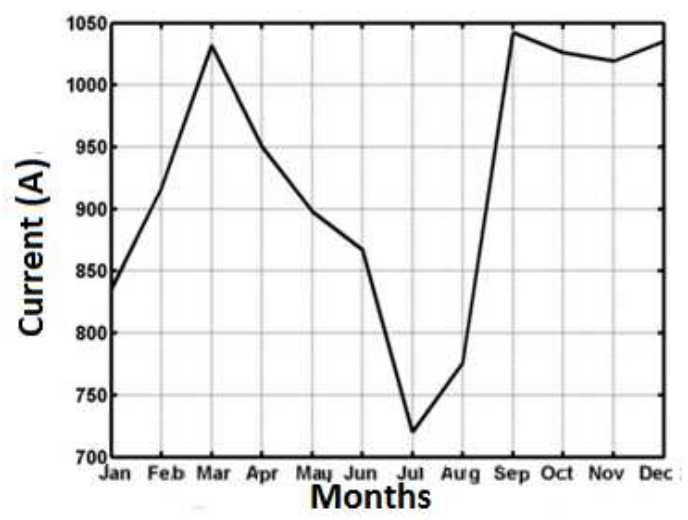

Fig. 5- Secondary phase current transformer 01 of $138 \mathrm{kV}$ / $13.8 \mathrm{kV}$ and 25 MVA substation in the city of Rondonópolis.

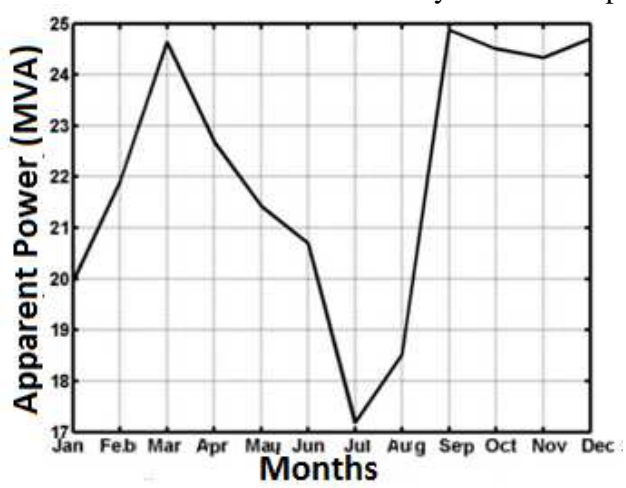

Fig. 6- Apparent power of the transformer 01 of $138 \mathrm{kV} /$ $13.8 \mathrm{kV}$ and 25 MVA substation in the city of Rondonópolis. 


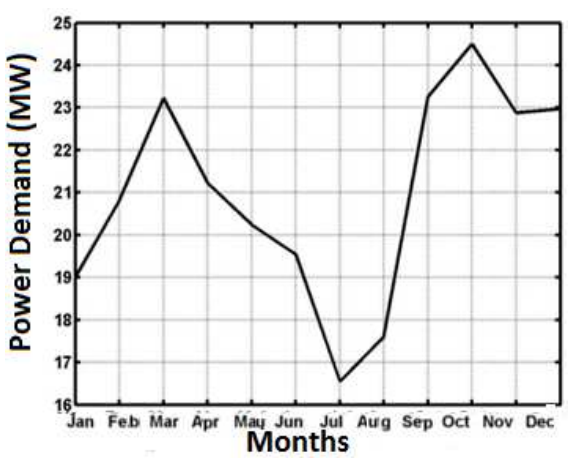

Fig. 7- Demand for active power transformer 01 of $138 \mathrm{kV} / 13.8$ $\mathrm{kV}$ and 25 MVA substation in the city of Rondonópolis.

The weather file and the municipality of Rondonópolis using EnergyPlus software to draw the profile of the average monthly temperature for the year 2012 is illustrated in figure 8 .

Analyzing figure 8, there is an increase in temperature in the months of September, October and November which coincides, as shown in figure 7 , with a significant increase in demand for active power transformer 01 of the substation of the city of Rondonópolis during September, October and November, provided by the climatic conditions of the region and associated activities related to agribusiness.

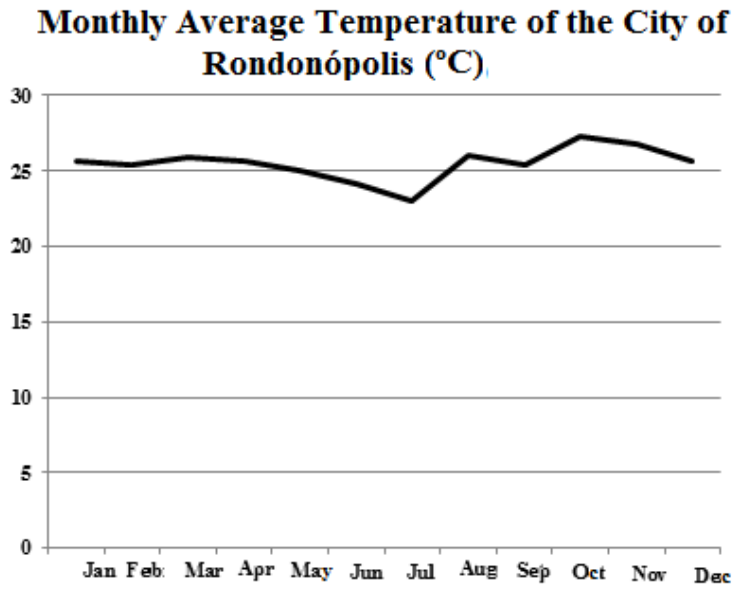

Fig. 8 - Monthly Average Temperature of the city of Rondonópolis

\section{Proposed model for fragmented mobile substation}

Figure 9 illustrates a summarized schematic diagram of a conventional mobile substation composed of protection along with the transformer and other accessories.

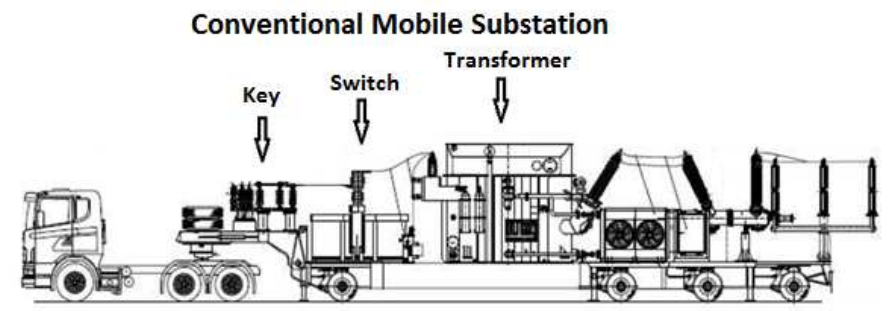

Fig. 9 - Summary schematic diagram of a conventional mobile substation.
As can be seen, the structure of the arrangement shows that in a region dominated by unpaved roads and that its displacement would be consistent with its use, which is to meet emergency situations and seasonality of loads of agribusiness which is in regions of difficult access, as is the case with some concession areas that are part of the local Company of Electricity in the state of Mato Grosso. Table II illustrates the trafficability conditions contained in Resolution No. 11 DNIT [2], published on October 25 th, 2004, ratified on January $1^{\text {st }}, 2005$ and June $16^{\text {th }}$, 2005 , which deals with the authorization of mobility trucks on the highways from certain weight, height, width and length. As can be seen, most conventional mobile substations do not have free trafficability conditions under the law [10] - [11].

TABLE II - Trafficability conditions - DNIT

\begin{tabular}{|c|c|c|c|c|}
\hline Condition & $\begin{array}{c}\text { Weight } \\
(\mathbf{t})\end{array}$ & $\begin{array}{c}\text { Width } \\
(\mathbf{m})\end{array}$ & $\begin{array}{c}\text { Height } \\
(\mathbf{m})\end{array}$ & $\begin{array}{c}\text { Length } \\
(\mathbf{m})\end{array}$ \\
\hline Free Traffic & $\leq 45$ & $\leq 2,60$ & $\leq 4,40$ & $\leq 19,80$ \\
\hline $\begin{array}{c}\text { Annual } \\
\text { permit (free } \\
\text { traffic during } \\
\text { 24 hours of } \\
\text { the day) }\end{array}$ & $\leq 57$ & $\leq 3,00$ & $\leq 4,40$ & $\leq 23,00$ \\
\hline $\begin{array}{c}\text { Annual } \\
\text { permit (only } \\
\text { traffic allowed } \\
\text { from sunset to } \\
\text { sunrise) }\end{array}$ & $\leq 57$ & $\leq 3,20$ & $\leq 4,40$ & $\leq 23,00$ \\
\hline $\begin{array}{c}\text { Authorization } \\
\text { required for } \\
\text { each shift }\end{array}$ & $\leq 74$ & $\leq 3,20$ & $\leq 4,40$ & $\leq 23,00$ \\
\hline $\begin{array}{c}\text { Authorization } \\
\text { required for } \\
\text { each shift + } \\
\text { scouts to } \\
\text { escort and / or } \\
\text { police escort }\end{array}$ & $>74$ & $>3,20$ & $>4,40$ & $>23,00$ \\
\hline
\end{tabular}

The purpose of this study as shown in figure 10 , it is the separation of conventional structure shown in figure 9, that is, a mechanical horse with its respective carriage carrying a mobile transformer that can meet emergency and seasonal loads in regions of difficult access and trafficability or when they need maintenance or replacement of the equipment with mechanical or electrical problems, and a second tractor trailer hauling part made up of key protection, lightning rod and breaker of high and low voltage that may be used to meet also emergencies substation protection of difficult access and trafficability [10] - [11]. 


\section{Fragmented Mobile Substation}
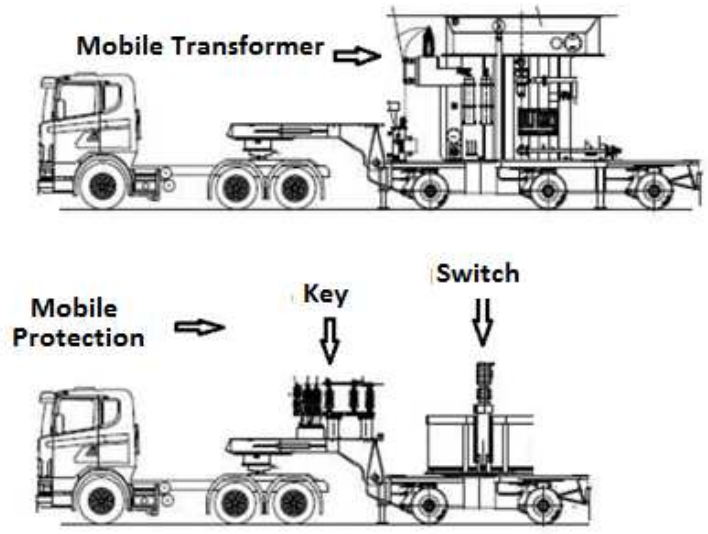

Fig. 10 - Schematic summary of a fragmented mobile substation.

In addition to solving the issue of trafficability, due to the fragmentation and size, there is also concern about the environment. Thus, the proposal of this work also aims to replace the insulating oil (IMO) used in the windings of conventional power transformers by high vegetable oil insulator (OVI) [3] - [4].

As the fragmented mobile substation will travel through various regions of unpaved local roads lined with rivers and streams, the mineral oil used in the transformer can cause environmentally contaminated areas due to occasional accidents, being then replaced by vegetable oil whose possible environmental damage will be minimized.

The vegetable oil is a fat consisting of triglycerides and extracted from plants. Although, in principle, other plant parts can be used in oil extraction, in practice it is extracted mostly (almost exclusively) of seeds.

The substitution of mineral insulating oils of vegetable origin for fluids in power transformers has aroused a high degree of interest in recent years. This is due to several factors such as the high flash point, high hygroscopic, which may allow the insulation paper keep drier, nontoxicity and biodegradability, that make it attractive from an environmental point of view, among other features.

Vegetable oils are based on organic esters, natural agricultural products or chemically synthesized by organic precursor compounds. Dielectric fluids based on synthetic ester possess good dielectric characteristics and are more biodegradable than mineral oil based hydrocarbons of high molecular power. Moreover, it has excellent thermal stability, good properties at high temperatures, pour point close to the conventional mineral oil and the like and the dielectric strength formulation with natural ester viscosities. Its high cost compared to other fire resistant fluids, generally limits their use to mobile substations, traction transformers and other special applications. The natural ester has slightly higher viscosity than mineral oil, greater fire resistance and higher dielectric strength, both in new fluid as after multiple switching operations under load. The downside is its relatively high pour point.

An attractive source of natural esters are seed oils. Widely available and low cost of production, these seeds (derived from renewable natural sources, unlike mineral oils) are used primarily in foodstuffs. The formulation of vegetable oil shows no toxicity to humans and has much shorter than the mineral oils degradation. Furthermore, the products of complete combustion are carbon dioxide and water only. The fluid can be filtered and recycled easily disposable.

A relevant question to the adoption of the vegetable oil in transformers is the durability of the insulating paper as shown in figure 11 , that is, how the new insulating fluid affects the useful life of the solid insulation [3] - [4].

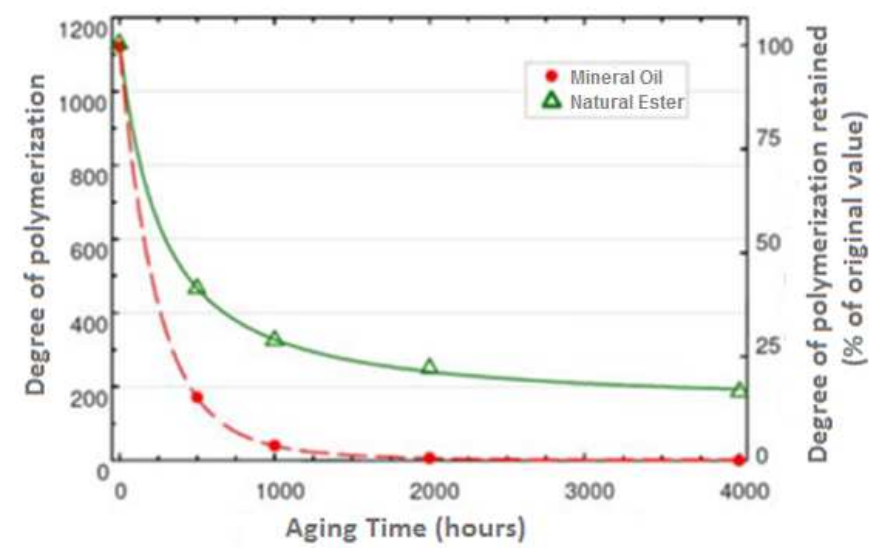

Fig. 11 - Comparison of aging of the insulating paper with different fluids [3].

The mineral insulating oil (IMO) is a product derived from petroleum, which is a finite source, whereas the vegetable oil insulator (OVI) is obtained from oilseeds such as corn, sunflower, soybean, etc., which are renewable. When leaks occur, IMO contaminates the soil and water systems because of their slow biodegradation process. Because it is formulated from natural raw materials, the OVI is readily biodegradable in the environment, thus making it an excellent option for companies who care about the preservation of the environment.

During use of the insulating oil in the machine, it is subject to an oxidation process, forming acids as final degradation products that can be measured by means of acid number. In the case of IMO, these compounds from certain concentration are undesirable because they attack the equipment materials, especially kraft insulating paper, reducing thereby its useful life. Such compounds can also polymerize and form sludge, which is deposited on the active part or heat exchangers, hinders the transfer of heat to the environment. The neutralization indices of Ovis are usually higher than those of the IMO. Ovis oxidized tend to form long chain fatty acids while the IMO tends to form short-chain organic acids, which are more aggressive.

The moisture in the IMO acts as a catalyst in the decomposition of cellulose, decreasing therefore the service life of electrical equipment. Due to its chemical nature, OVI has great affinity for water. This property contributes to the increased lifetime of the solid insulation. In applications where risk of fire and explosion must be minimized is recommended to use fluids safely. To be considered fluid security, the insulating liquid must have a flash point of at least $300^{\circ}$ C. As ovis feature points above $300^{\circ} \mathrm{C}$ combustion, these fluids are considered security, unlike IMO having a flash point about $150^{\circ} \mathrm{C}$. OVI isolated equipment do not 
present risk of failure due to corrosive sulfur. OMIS have organic sulfur-based compounds.

The use of the OVI is a reality in the electricity sector. Its use in distribution transformers is consolidated. The use of power equipment is being investigated by several utilities and research institutions. With the expansion of its use, the electricity sector will be contributing to the maintenance of the environment and the sustainability of the country.

\section{Conclusion}

This paper discussed the development of a fragmented mobile substation, whereas currently existing mobile substations on the market are characterized by a unique set involving protection, transformer and others. This set has considerable weight and size, making it difficult to trafficability and mobility, due to the need for followbeaters and special licensing, besides not being allowed their locomotion in the night period, experiencing a delay in emergency care. Furthermore, most of the transmission lines that serve the various regions of the state of Mato Grosso is part of a radial system is not providing alternative care in the event of emergency in fixed substations. This new proposal will provide a faster service by avoiding penalties incident indicators of continuity, and diversity into emergency care, as you may be applying the individual component parts. It can meet stationary substations that have problems only in the protection and/or switching, as well as in meeting peak demands in certain areas of the state due to the characteristics of industries that comprise the agribusiness. It was also found that the replacement of the mineral oil by vegetable oil has technical advantages and reduces potential damage to the environment during the displacement of the mobile substation.

\section{REFERENCES}

[1] ANEEL. Normative Resolution 3987 of March 19, 2013.

[2] DNIT (National Department of Transport Infrastructure). Resolution 11.

[3] S. M. Melo. Study of the Application of Vegetable Oil as Insulating Oil in Electrical Transformer. Federal University of Piauí, 2008.

[4] M. B. C. STOCCO. Evaluation of the Potential Application of Vegetable Oil as Insulating Fluids in Transformers Distribution Mains. Curitiba, 2009.

[5] Brazilian Association of Technical Standards - ABNT. NBR 5356 - August 1993 - Power Transformer - Specification.

[6] Brazilian Association of Technical Standards - ABNT. NBR 8153 - August 1993 - Power Transformer - Specification.

[7] Massachusetts Institute of Technology Staff. Magnetics Circuits and Transformers. The MIT Press, fifteenth printing, 1965.

[8] Fitzgerald. A. E. Electrical Machines. Publisher McGrawHill's Brazil 1975.

[9] J. O. C. Fandi. Modeling of Transformers Three Columns Studies Inrush Current. Thesis, Federal University of Uberlândia, 2003.

[10] Christof Devriendt, Patrick Guillaume, Jose Lopez-Roldanb. Structural dynamics of a mobile substation during transport. Engineering Structures, 2007.

[11] R. F. Stevens, A. A. Straub, V. J. Hayes. Working Group Report on Mobile Substations-Their Use and the Design Or
Distribution Substations to Facilitate Their Use. AIEE COMMITTEE REPORT, 1958. 